\title{
Comparison of the effect of a combination of eight micronutrients versus a standard mono preparation on sperm parameters
}

\author{
Markus Lipovac ${ }^{1,2^{*}}$ (D), Florian Bodner ${ }^{1,2}$, Martin Imhof ${ }^{1,2,3}$ and Peter Chedraui ${ }^{4}$
}

\begin{abstract}
Background: There are reports showing that I-carnitine alone or in combination with other micronutrients improve sperm parameters. However, comparative studies are still lacking. This study was carried out to compare the short term effects of a combination of eight micronutrients including I-carnitine vs. a mono-substance (I-carnitine alone) on sperm parameters.
\end{abstract}

Methods: This was a prospective, open-labelled, nonrandomized study that included male subjects (20 to 60 years) with at least 1 year of subfertility and at least one pathological semen analysis who received 3 months treatment with a mono-substance (500 $\mathrm{mg}$ l-carnitine/twice a day, $n=156)$ or a combined compound (440 $\mathrm{mg}$ l-carnitine + $250 \mathrm{mg}$ l-arginine $+40 \mathrm{mg}$ zinc $+120 \mathrm{mg}$ vitamin E + $80 \mathrm{mg}$ glutathione $+60 \mu \mathrm{g}$ selenium + $15 \mathrm{mg}$ coenzyme Q10 $+800 \mu \mathrm{g}$ folic acid/once a day, $n=143)$ for the same time period. Sperm parameters were analyzed before and after treatment and groups comparisons performed.

Results: Baseline characteristics were similar among studied groups (age and body mass indices). Semen parameters (volume, density, overall progressive motility [including slow and fast motility]) and percentage of sperm with normal morphology improved after 3 months in both groups as compared to baseline. However, relative change (expressed as \% increase of absolute values) for sperm density and overall progressive motility (including fast motility) was found to be higher for the combined micronutrient treatment group as compared to the mono-treatment using l-carnitine alone.

Conclusion: Both analyzed groups displayed a positive short term effect on all sperm parameters; however effect on density and motility was significantly better for the combined formulation. There is need for more research in this matter that includes long term outcome data.

Trial registration: Retrospectively registered at ISRCTN (7th October 2016). Study ID: ISRCTN48594239

Keywords: Sperm parameters, Combined treatment, Mono-treatment, Micronutrients, I-carnitine

\section{Background}

At the peak of reproductive capability, a healthy couple has an annual pregnancy probability rate of $80-85 \%$. Nevertheless, $10-15 \%$ of couples trying to achieve pregnancy remain childless [1]. Male factor accounts for nearly half of cases of infertility presenting an abnormal

\footnotetext{
* Correspondence: markus@lipovac.at

${ }^{1}$ IMl Fertility Center, Vienna, Austria

${ }^{2}$ Karl Landsteiner Institute for cell-based therapy in Gynecology, Wiener Ring

3-5, 2100 Korneuburg, Austria

Full list of author information is available at the end of the article
}

semen analysis. In $45 \%$ of sub-/infertile men, this disorder is of unexplained (unidentified) origin [2, 3].

Reports indicate that sperm quality has declined over the past decades $[4,5]$. Mainly, this fact seems to be the result of certain nutritional deficiencies and adverse environmental and lifestyle factors [6, 7]. Various micronutrients [8-11] are directly or indirectly involved in sperm metabolism; and nutrient deficiencies can lead to impaired sperm quality $[12,13]$. Ionising radiation, genital infections and alcohol, cigarette or illicit drug consumption can cause intrinsic toxicity and generate intense body oxidative stress. The negative impact of 
reactive oxygen species (ROS) has been recognized as a main cause of idiopathic infertility $[14,15]$. Free radicals damage spermatic nuclear and mitochondrial genetic information producing strand breaks in the DNA $[16,17]$; thus, impairing their mobility and morphology through lipid peroxidation of the plasma membrane, and compromising sperm cell and oocyte interaction [18-20].

In a Cochrane review, it has been reported that antioxidant supplementation in sub-fertile males may improve the outcomes of live birth and pregnancy rate for sub-fertile couples undergoing ART cycles [17]. The suspected mechanism of action is the improvement of sperm quality through the alleviation of the nutrient deficiency as well as the reduction of oxidative stress [21]. The sum of these effects leads to a higher chance of pregnancy, an undisturbed intrauterine development and a certain inherent protection of the newborn [22-33].

Previous studies have assessed the use of 1-carnitine alone as well as various combination therapies as an effective way of improving semen analysis results [34-42]. However, a direct contrast with a combination of various micronutrients and, consequently, a quantification of the effects, has not yet been assessed in the framework of a research study. Hence, the aim of the present investigation was to compare the short term effect of a combination of eight micronutrients (including l-carnitine) vs. a standard mono-substance (l-carnitine alone) on sperm parameters.

\section{Methods}

This was a prospective, open-labelled, non-randomized study that included male subjects consulting according to inclusion criteria between January 2005 and January 2014 at the IMI Fertility Center and the Med19 Study Center of Vienna, Austria.

A total of 299 participants who met inclusion criteria: 20 to 60 years of age, suffering from at least 1 year of subfertility and had at least one recent pathological semen analysis result (up to 3 months, considered baseline) were invited to participate for 3 months to receive treatment with a mono-substance (500 mg l-carnitine/ twice a day, $n=156)$ or a combined compound (440 mg l-carnitine + $250 \mathrm{mg} \mathrm{l-arginine}+40 \mathrm{mg}$ zinc + $120 \mathrm{mg}$ vitamin $\mathrm{E}+80 \mathrm{mg}$ glutathione $+60 \mu \mathrm{g}$ selenium $+15 \mathrm{mg}$ coenzyme Q10 + $800 \mu \mathrm{g}$ folic acid/once a day, $n=143 ;$ Profertil $^{\circ}$, Lenus Pharma GmbH, Vienna, Austria) for the same period of time. A second semen analysis was performed after 3 months. Subjects were encouraged to refrain from the consumption of other micronutrients during the study period. Exclusion criteria were: azoospermia, aspermia, varicocele, recent urogenital infections, and hormonal disorders.

The following sperm parameters were analysed at baseline and after treatment: sperm volume $(\mathrm{ml})$ and density $(\mathrm{mio} / \mathrm{ml})$, overall, fast and slow progressive motility (expressed as \%), and \% of sperm with normal morphology. All parameters were defined according to WHO guidelines (4th edition). Local ethical approval was obtained for this study which was retrospectively registered at ISRCTN (7th October 2016). Study ID: ISRCTN48594239 www.isrctn.com. All subjects were informed of the research, its objectives and provided signed consent of participation and publication of individual patient data. Pseudonymisation and access restrictions were used in order to avoid public access to the sensitive patient data.

Statistical analysis was performed with the Statistical Package for the Social Sciences version 22.0 (IBM SPSS, Armonk, NY, USA). All data are presented as mean \pm standard deviations. The Kolmogorov Smirnov test was used to assess the normality of data distribution. For each measured variable and each case changes from baseline (increase, decrease or none) were calculated as absolute (subtraction of 3rd month value minus baseline) or relative values (the percent expression of each calculated absolute value). Paired Student's $T$ test was used for intragroup comparisons. Non paired Student's $T$ test or the Mann Whitney $U$ test was used for intergroup comparisons. A $p$ value of $<0.05$ was considered as statistically significant.

\section{Results}

Age ranged from 20 to 60 years in both groups, displaying similar median age and body mass indices. Other baseline characteristics such alcohol and tobacco consumption were similar among studied groups. The effect of each treatment on semen parameters after 3 months is presented in Table 1. It was observed that all studied sperm parameters (volume, density, overall progressive motility [including slow and fast motility]) and \% of sperm with normal morphology significantly improved after 3 months of treatment in both groups as compared to baseline. However, relative change (expressed as \% increase of absolute values) for sperm density and overall progressive motility (including fast motility) was found to be higher for the combined micronutrient treatment group as compared to the mono-treatment group using l-carnitine alone. Worth to note was the fact that the baseline slow- and fast progressive motility and \% of normal morphology were significantly different between studied groups.

\section{Discussion}

The effect of the administered mono-substance composed of the hydrophile molecule l-carnitine can be ascribed to its properties as a radical catcher in the mitochondrial membrane. By substitution anti-oxidative capacity in the seminal plasma increases significantly [43]. Moreover, 
Table 1 Semen parameters before and after 3 months according to each treatment group

\begin{tabular}{|c|c|c|c|c|c|c|c|c|}
\hline & \multicolumn{4}{|c|}{ Mono treatment $n=156$} & \multicolumn{4}{|c|}{ Combined treatment $n=143$} \\
\hline & Basal & 3 months & Absolute change ${ }^{a}$ & Relative change (\%) ${ }^{b}$ & Basal & 3 months & Absolute change $^{a}$ & Relative change (\%) ${ }^{b}$ \\
\hline Sperm volume (ml) & $3.0 \pm 1.2$ & $3.5 \pm 1.5^{*}$ & $0.5 \pm 1.6$ & $35.2 \pm 75.3$ & $2.9 \pm 1.2$ & $3.6 \pm 1.4^{*}$ & $0.7 \pm 1.4$ & $41.5 \pm 74.3$ \\
\hline Sperm density (mio/ml) & $28.5 \pm 19.0$ & $34.2 \pm 21.7^{*}$ & $5.7 \pm 21.3$ & $63.7 \pm 158.0$ & $24.9 \pm 16.2$ & $32.8 \pm 20.0^{*}$ & $7.9 \pm 23.5$ & $157.7 \pm 400.4^{* *}$ \\
\hline Overall progressive motility (\%) & $35.7 \pm 15.8$ & $44.9 \pm 19.9^{*}$ & $9.2 \pm 18.6$ & $44.0 \pm 90.3$ & $33.4 \pm 14.6$ & $48.6 \pm 17.6^{*}$ & $15.2 \pm 17.9^{* *}$ & $80.3 \pm 142.5^{* *}$ \\
\hline fast progressive motility (\%) & $16.7 \pm 10.6$ & $23.0 \pm 14.0^{*}$ & $6.3 \pm 16.0$ & $87.4 \pm 184.0$ & $10.3 \pm 9.4^{* *}$ & $20.4 \pm 13.1^{*}$ & $10.1 \pm 15.0^{* *}$ & $259.3 \pm 389.1^{* *}$ \\
\hline slow progressive motility (\%) & $19.2 \pm 12.7$ & $22.2 \pm 13.1^{*}$ & $2.9 \pm 12.8$ & $125.9 \pm 384.9$ & $23.1 \pm 12.9^{* *}$ & $28.3 \pm 12.2^{*, * *}$ & $5.1 \pm 12.7$ & $102.9 \pm 261.5$ \\
\hline Normal morphology (\%) & $17.9 \pm 14.0$ & $27.5 \pm 16.1^{*}$ & $9.6 \pm 17.8$ & $230.3 \pm 668.1$ & $26.2 \pm 15.6^{* *}$ & $35.9 \pm 16.1^{* * * *}$ & $9.7 \pm 19.4$ & $307.1 \pm 1,012.2$ \\
\hline
\end{tabular}

Data are presented as mean \pm standard deviations
${ }^{*} p$ value $<0.001$ as compared to basal as determined with the paired Student's $T$ test

$p$ value $<0.001$ as compared to basal as determined with the paired Student's $T$ test
${ }_{*}^{*} p$ value $<0.05$ as compared to mono treatment as determined with the non paired Student's $T$ test

a Absolute change for each variable and case was calculated subtracting third month value minus basal one

$\mathrm{b}$ relative change is the percent expression of each calculated absolute value 
studies in animals have shown that the molecule has protective effects on testicular tissue which has been exposed to ionising radiation $[44,45]$. This realisation can have a relevant effect on sperm quality in certain daily situations. Both effects serve as an explanation model for the positive influence of l-carnitine on sperm concentration, motility and morphology [34, 46, 47]. Consistent with these studies, our study found that l-carnitine alone or in combination with seven other micronutrients displayed short term improvement of all studied sperm parameters. Nevertheless, the combined preparation showed better results through a higher percent increase for sperm density and overall progressive motility (including fast motility) as compared to l-carnitine alone. To the best of our knowledge this research may be the first to prospectively compare the short-term effects of a mono treatment versus a combined product on sperm parameters.

The effect of the combination substance is to be seen as the sum of the partly augmentative effects of each component. The water-soluble l-arginine has a positive effect on sperm parameters such as motility and vitality $[48,49]$. The hydrophile coenzyme Q10 catches free radicals, and improves male FSH and LH serum profile $[9,50]$ and shows an improvement over sperm concentration, motility and morphology $[9,51]$. The hydrophile dietary mineral zinc provides a protective antioxidant effect during sperm production that may counteract against copper excess $[52,53]$, improving sperm cell concentration and motility [54-57]. Hydrophile folic acid reduces the concentration of round cells in the semen which are a major source for free radicals $[58,59]$; and hence leading to a reduction of oxidative stress [60] as well as a rise in sperm cell concentration [61]. Furthermore, there is evidence that folic acid could compensate for adverse influences of hypothyroidism and thyrostatic substances on testicular tissue [62, 63]. Selenium reduces oxidative stress [64] as it is bound as a structural element in the sperm cell membrane in form of the enzymes selenoprotein mGPx4 and snGPx4 [65]. Moreover, it optimizes thyroid metabolism important for sperm production and has a positive influence on autoimmune processes [66]. Selenium intake improves sperm motility [67] and morphology [65]. The watersoluble glutathione reduces oxidative stress significantly [68] which leads to an increase of progressive and morphologically normal sperm cells [38]. Regarding oxidative stress, one study found that 1carnitine improved sperm motility in asthenozoospermic men with normal levels of phospholipid hydroperoxide glutathione peroxidase, an important enzyme that minimizes oxidative stress [69]. The liposoluble vitamin $\mathrm{E}$ as component of the human cell membrane acts as oxidative protector for likewise located unsaturated fatty acids [70]. Vitamin E supplementation reduces lipid peroxidation, therefore improving sperm motility significantly [21]. This antioxidative effect may potentiate the beneficial effects of l-carnitine. Indeed, one study found that the combination of 1-carnitine (2 g per day) and vitamin $\mathrm{E}$ improved sperm motility in asthenozoospermic men; effect which was not observed among those taking vitamin $\mathrm{E}$ alone [71].

L-carnitine seems not the sole actor in sperm production. As already mentioned, the combined compound displayed a better improvement of sperm density and overall progressive motility. This is important because motility seems to be a key parameter of male fertility. The diverse target points for eight micronutrients and their partially synergistic cooperation in different body compartments serve as an explanatory model for its selective superiority as compared to the mono-therapy with l-carnitine alone. It is still unclear whether motility improvement exerted by combined compound is due to enhanced oxidative stress suppression or to the sum of the specific singular effects of each compound.

Authors acknowledge that the study has limitations. Indeed, although data is prospective, its open-labelled and non-randomized nature is a potential source of bias. On the other hand, this document does not present final outcome of pregnancies; however, this was not the primary endpoint aim of this study arm. Data related to outcome of pregnancy, as a secondary end-point, will be presented elsewhere.

Despite these limitations, prospective comparative data regarding the efficacy of mono-treatment and combined compound on sperm parameters are lacking. Hence, this may be seen as a potential strength of our study. Nevertheless, there is need for well controlled prospective randomized data.

\section{Conclusion}

Overall effect on sperm parameters was similar in both analyzed groups; however, in the combined-formulation group improvement of sperm density, overall and fast progressive motility was significantly better than those in the mono-preparation group. There is a need for more research in this matter that include pregnancy outcome data.

Abbreviations

ART: Assisted reproductive technology; ROS: Reactive oxygen species; WHO: World Health Organization

\section{Acknowledgements}

Authors would like to thank participants of the study.

Funding

None. 


\section{Availability of data and materials}

Raw data and materials available on request at the authors

\section{Authors' contributions}

$M L, F B$ and $M l$ planned the study. ML and FB performed recruitment and clinical follow-up. ML and PCH participated in the analysis of data and discussion of the results. ML, MI and PCH drafted final manuscript. All authors have read and approved the final version of the document.

\section{Competing interests}

The authors declare that they have no competing interests.

\section{Consent for publication}

We have obtained consent to publish from the participants to report individual patient data

\section{Ethics approval and consent to participate}

Local ethical approval was obtained for the study. Every patient signed a written consent form before participating in the study.

\section{Author details}

${ }^{1}$ IMI Fertility Center, Vienna, Austria. ${ }^{2}$ Karl Landsteiner Institute for cell-based therapy in Gynecology, Wiener Ring 3-5, 2100 Korneuburg, Austria. ${ }^{3}$ Medical University of Vienna, Vienna, Austria. ${ }^{4}$ Institute of Biomedicine, Research Area for Women's Health, Facultad de Ciencias Médicas, Universidad Católica de Santiago de Guayaquil, Guayaquil, Ecuador.

\section{Received: 7 October 2016 Accepted: 2 December 2016}

\section{Published online: 09 December 2016}

\section{References}

1. Breckwoldt M, Kaufmann M, Pfleiderer A. (Hg.). Gynäkologie und Geburtshilfe. Stuttgart: Georg Thieme Verlag; 2008.

2. Cavallini G. Male idiopathic oligoasthenoteratozoospermia. Asian J Androl. 2006:8:143-57

3. Hancke K, Denschlag D, Gitsch G, Keck C. Therapeutische Ansätze bei idiopathischer Infertilität des Mannes. Geburtshilfe Frauenheilkd. 2006;66: 26-33.

4. Carlsen E, Giwercman A, Keiding N, Skakkebaek NE. Evidence for decreasing quality of semen during past 50 years. BMJ. 1992;305:609-13.

5. Osser S, Liedholm P, Ranstam J. Depressed semen quality: a study over two decades. Arch Androl. 1984;12:113-6.

6. Agarwal A, Prabakaran SA. Mechanism, measurement, and prevention of oxidative stress in male reproductive physiology. Indian J Exp Biol. 2005;43: 963-74.

7. De Celis R, Pedrón-Nuevo N, Feria-Velasco A. Toxicology of male reproduction in animals and humans. Arch Androl. 1996:37:201-18.

8. Glander HJ, Paasch U, Grunewald S. Medikamtöse Therapieansätze zur Behandlung der männlichen Infertilität. Blickpunkt der Mann. 2007;5:19-24.

9. Safarinejad MR. Efficacy of coenzyme Q10 on semen parameters, sperm function and reproductive hormones in infertile men. J Urol. 2009;182: 237-48.

10. Balázs C, Rácz K. The role of selenium in endocrine system diseases. Orv Hetil. 2013;154:1628-35.

11. Garratt M, Bathgate R, de Graaf SP, Brooks RC. Copper-zinc superoxide dismutase deficiency impairs sperm motility and in vivo fertility. Reproduction. 2013;146:297-304.

12. Ochsendorf FR, Buhl R, Bästlein A, Beschmann H. Glutathione in spermatozoa and seminal plasma of infertile men. Hum Reprod. 1998;13:353-9.

13. Fertilitätsstörung: Spoiler am Sperma, Doccheck news, 7th Feb. 2014. http:// news.doccheck.com/de/37578/fertilitaetsstoerung-spoiler-am-sperma.

14. Agarwal A, Saleh RA, Bedaiwy MA. Role of reactive oxygen species in the pathophysiology of human reproduction. Fertil Steril. 2003;79:829-43.

15. Khosrowbeygi A, Zarghami N. Levels of oxidative stress biomarkers in seminal plasma and their relationship with seminal parameters. BMC Clin Pathol. 2007:7:6.

16. Sawyer DE, Mercer BG, Wiklendt AM, Aitken RJ. Quantitative analysis of gene-specific DNA damage in human spermatozoa. Mutat Res. 2003; 529:21-34.
17. Showell MG, Brown J, Yazdani A, Stankiewicz MT, Hart RJ. Antioxidants for male subfertility. Cochrane Database Syst Rev. 2011;1, CD007411.

18. Aitken RJ, Clarkson JS, Fishel S. Generation of reactive oxygen species, lipid peroxidation, and human sperm function. Biol Reprod. 1989:41:183-97.

19. Agarwal A, Allamaneni SS, Said TM. Chemiluminescence technique for measuring reactive oxygen species. Reprod Biomed Online. 2004:9:466-8.

20. Aitken RJ, Harkiss D, Buckingham DW. Analysis of lipid peroxidation mechanisms in human spermatozoa. Mol Reprod Dev. 1993;35:302-15.

21. Suleiman SA, Ali ME, Zaki ZM, el-Malik EM, Nasr MA. Lipid peroxidation and human sperm motility: protective role of vitamin E. J Androl. 1996;17:530-7.

22. Sukcharoen N, Keith J, Irvine DS, Aitken RJ. Predicting the fertilizing potential of human sperm suspensions in vitro: importance of sperm morphology and leukocyte contamination. Fertil Steril. 1995;63:1293-300.

23. Hansen M, Kurinczuk JJ, Bower C, Webb S. The risk of major birth defects after intracytoplasmic sperm injection and in vitro fertilization. N Engl J Med. 2002;346:725-30

24. Carrell DT, Liu L, Peterson CM, Jones KP, Hatasaka HH, Erickson L, et al. Sperm DNA fragmentation is increased in couples with unexplained recurrent pregnancy loss. Arch Androl. 2003:49:49-55.

25. Baker MA, Aitken RJ. Reactive oxygen species in spermatozoa: methods for monitoring and significance for the origins of genetic disease and infertility. Reprod Biol Endocrinol. 2005;3:67.

26. Lewis SE, Aitken RJ. DNA damage to spermatozoa has impacts on fertilization and pregnancy. Cell Tissue Res. 2005;322:33-41.

27. Ji BT, Shu XO, Linet MS, Zheng W, Wacholder S, Gao YT, et al. Paternal cigarette smoking and the risk of childhood cancer among offspring of nonsmoking mothers. J Natl Cancer Inst. 1997;89:238-44.

28. Crow JF. The origins, patterns and implications of human spontaneous mutation. Nat Rev Genet. 2000;1:40-7.

29. Sipos A, Rasmussen F, Harrison G, Tynelius P, Lewis G, Leon DA, Gunnell D. Paternal age and schizophrenia: a population based cohort study. BMJ. 2004:329:1070

30. Vestergaard M, Mork A, Madsen KM, Olsen J. Paternal age and epilepsy in the off-spring. Eur J Epidemiol. 2005;20:1003-5.

31. Reichenberg A, Gross R, Weiser M, Bresnahan M, Silverman J, Harlap S, et al. Advancing paternal age and autism. Arch Gen Psychiatry. 2006:63:1026-32.

32. Aitken RJ, De luliis GN, McLachlan RI. Biological and clinical significance of DNA damage in the male germ line. Int J Androl. 2009:32:46-56.

33. Gharagozloo P, Aitken RJ. The role of sperm oxidative stress in male infertility and the significance of oral antioxidant therapy. Hum Reprod. 2011;26:1628-40.

34. Lenzi A, Lombardo F, Sgrò P, Salacone P, Caponecchia L, Dondero F, et al. Use of carnitine therapy in selected cases of male factor infertility: a doubleblind crossover trial. Fertil Steril. 2003;79:292-300.

35. Zhou X, Liu F, Zhai S. Effect of L-carnitine and/or L-acetyl-carnitine in nutrition treatment for male infertility: a systematic review. Asia Pac J Clin Nutr. 2007:16:383-90.

36. Matalliotakis I, Koumantaki Y, Evageliou A, Matalliotakis G, Goumenou A, Koumantakis E. L-carnitine levels in the seminal plasma of fertile and infertile men: correlation with sperm quality. Int J Fertil Womens Med. 2000;45:236-40.

37. Balercia G, Mosca F, Mantero F, Boscaro M, Mancini A, Ricciardo-Lamonica G, et al. Coenzyme Q(10) supplementation in infertile men with idiopathic asthenozoospermia: an open, uncontrolled pilot study. Fertil Steril. 2004:81:93-8.

38. Lenzi A, Culasso F, Gandini L, Lombardo F, Dondero F. Placebo-controlled, double-blind, cross-over trial of glutathione therapy in male infertility. Hum Reprod. 1993;8:1657-62.

39. Netter A, Hartoma R, Nahoul K. Effect of zinc administration on plasma testosterone, dihydrotestosterone and sperm count. Arch Androl. 1981;7:69-73.

40. Imhof M, Matthai C, Huber JC. Einsatz von Profertil ${ }^{\oplus}$ zur Therapie des "Male factors" und Verbesserung des Spermiogramms. Gyn-Aktiv. 2007;2:68.

41. Stanislavov R, Rohdewald P. Sperm quality in men is improved by supplementation with a combination of L-arginine, L-citrullin, roburins and Pycnogenol ${ }^{\circledR}$. Minerva Urol Nefrol. 2014;66:217-23.

42. Wong WY, Merkus HM, Thomas CM, Menkveld R, Zielhuis GA, SteegersTheunissen RP. Effects of folic acid and zinc sulfate on male factor subfertility: a double-blind, randomized, placebo-controlled trial. Fertil Steril. 2002;77:491-8.

43. Balercia G, Regoli F, Armeni T, Koverech A, Mantero F, Boscaro M. Placebocontrolled double-blind randomized trial on the use of L-carnitine, $\mathrm{L}$-acetylcarnitine, or combined L-carnitine and L-acetylcarnitine in men with idiopathic asthenozoospermia. Fertil Steril. 2005:84:662-71. 
44. Ahmed MM, Ibrahim ZS, Alkafafy M, El-Shazly SA. L-carnitine protects against testicular dysfunction caused by gamma irradiation in mice. Acta Histochem. 2014;116:1046-55.

45. Topcu-Tarladacalisir Y, Kanter M, Uzal MC. Role of L-carnitine in the prevention of seminiferous tubules damage induced by gamma radiation: a light and electron microscopic study. Arch Toxicol. 2009:83:735-46.

46. Lenzi A, Sgrò P, Salacone P, Paoli D, Gilio B, Lombardo F, et al. A placebocontrolled double-blind randomized trial of the use of combined I-carnitine and I-acetyl-carnitine treatment in men with asthenozoospermia. Fertil Steril. 2004:81:1578-84.

47. Ahmed SD, Karira KA, Jagdesh, Ahsan S. Role of L-carnitine in male infertility. J Pak Med Assoc. 2011;61:732-6.

48. Hellstrom WJ, Bell M, Wang R, Sikka SC. Effect of sodium nitroprusside on sperm motility, viability, and lipid peroxidation. Fertil Steril. 1994;61:1117-22.

49. Zhang $H$, Zheng RL. Possible role of nitric oxide on fertile and asthenozoospermic infertile human sperm functions. Free Radic Res. 1996; 25:347-54.

50. James AM, Smith RA, Murphy MP. Antioxidant and prooxidant properties of mitochondrial Coenzyme Q. Arch Biochem Biophys. 2004:423:47-56

51. Safarinejad MR, Safarinejad S, Shafiei N, Safarinejad S. Effects of the reduced form of coenzyme Q10 (ubiquinol) on semen parameters in men with idiopathic infertility: a double-blind, placebo controlled, randomized study. J Urol. 2012;188:526-31.

52. Garcia PC, Piffer RC, Gerardin DC, Sankako MK, Alves de Lima RO, Pereira OC. Could zinc prevent reproductive alterations caused by cigarette smoke in male rats? Reprod Fertil Dev. 2012;24:559-67.

53. Babaei H, Abshenas J. Zinc therapy improves adverse effects of long term administration of copper on epididymal sperm quality of rats. Iran J Reprod Med. 2013;11:577-82.

54. Omu AE, Dashti H, Al-Othman S. Treatment of asthenozoospermia with zinc sulphate: andrological, immunological and obstetric outcome. Eur J Obstet Gynecol Reprod Biol. 1998;79:179-84.

55. Hartoma TR, Nahoul K, Netter A. Zinc, plasma androgens and male sterility. Lancet. 1977;2:1125-6.

56. Tikkiwal M, Ajmera RL, Mathur NK. Effect of zinc administration on seminal zinc and fertility of oligospermic males. Indian J Physiol Pharmacol. 1987;31: 30-4.

57. Lishko PV, Kirichok Y. The role of Hv1 and CatSper channels in sperm activation. J Physiol. 2010;588:4667-72.

58. Bentivoglio G, Melica F, Cristoforoni P. Folinic acid in the treatment of human male infertility. Fertil Steril. 1993;60:698-701.

59. Aitken RJ, De luliis GN. On the possible origins of DNA damage in human spermatozoa. Mol Hum Reprod. 2010;16:3-13.

60. Tunc O, Thompson J, Tremellen K. Improvement in sperm DNA quality using an oral antioxidant therapy. Reprod Biomed Online. 2009;18:761-8.

61. Landau B, Singer R, Klein T, Segenreich E. Folic acid levels in blood and seminal plasma of normo- and oligospermic patients prior and following folic acid treatment. Experientia. 1978;34:1301-2.

62. Ibrahim W, Tousson E, El-Masry T, Arafa N, Akela M. The effect of folic acid as an antioxidant on the hypothalamic monoamines in experimentally induced hypothyroid rat. Toxicol Ind Health. 2012;28:253-61.

63. Tousson E, Ali EM, Ibrahim W, Mansour MA. Treatment with folic acid ameliorated the histopathological alterations caused by propylthiouracil-induced hypothyroid rat testes. Toxicol Ind Health. 2012;28:566-76

64. Keskes-Ammar L, Feki-Chakroun N, Rebai T, Sahnoun Z, Ghozzi H, Hammami $S$, et al. Sperm oxidative stress and the effect of an oral vitamin $E$ and selenium supplement on semen quality in infertile men. Arch Androl. 2003; 49:83-94.

65. Ahsan U, Kamran Z, Raza I, Ahmad S, Babar W, Riaz MH, et al. Role of selenium in male reproduction - a review. Anim Reprod Sci. 2014;146:55-62.

66. Beckett GJ, Arthur JR. Selenium and endocrine systems. J Endocrinol. 2005; 184:455-65.

67. Vézina D, Mauffette F, Roberts KD, Bleau G. Selenium-vitamin E supplementation in infertile men. Effects on semen parameters and micronutrient levels and distribution. Biol Trace Elem Res. 1996; 53:65-83.

68. Kodama H, Yamaguchi R, Fukuda J, Kasai H, Tanaka T. Increased oxidative deoxyribonucleic acid damage in the spermatozoa of infertile male patients. Fertil Steril. 1997;68:519-24.
69. Garolla A, Maiorino M, Roverato A, Roveri A, Ursini F, Foresta C. Oral carnitine supplementation increases sperm motility in asthenozoospermic men with normal sperm phospholipid hydroperoxide glutathione peroxidase levels. Fertil Steril. 2005;83:355-61.

70. Horn F, Moc I, Schneider N, Grillhösl C, Berghold S, Lindenmeier G. (Hg.). Biochemie des Menschen. 2005. p. 3.

71. Wang YX, Yang SW, Qu CB, Huo HX, Li W, Li JD, et al. L-carnitine: safe and effective for asthenozoospermia. Zhonghua Nan Ke Xue. 2010;16:420-2.

\section{Submit your next manuscript to BioMed Central and we will help you at every step:}

- We accept pre-submission inquiries

- Our selector tool helps you to find the most relevant journal

- We provide round the clock customer support

- Convenient online submission

- Thorough peer review

- Inclusion in PubMed and all major indexing services

- Maximum visibility for your research

Submit your manuscript at www.biomedcentral.com/submit
Biomed Central 